\title{
Cluster designation 5 staining of normal and non-lymphoid neoplastic skin*
}

Background: Immunohistochemical staining for cluster designation 5 (CD5) has been found to label a variety of non-lymphoid tumors. Methods: A variety of eccrine, apocrine, follicular, epithelial, and pagetoid lesions were selected and stained with an anti-CD5 monoclonal antibody (Novocastra Labs, Newcastle upon Tyne, UK, clone 4C7) by immunohistochemistry. The intensity of positive cytoplasmic staining was graded semiquantitatively (1+ weak staining, $2+$ strong staining). Additionally, the percentage of positive lesional cells was placed in one of four categories: $>75 \%, 25-75 \%, 1-25 \%$, and $<1 \%$.

Results: Within normal skin, CD5 labeled lymphocytes, apocrine glands, deep dermal eccrine glands, and smooth muscle (weak). The majority of benign and malignant apocrine lesions demonstrated strong focal $(36 \%, \mathrm{n}=11)$-to-diffuse $(64 \%, \mathrm{n}=16)$ staining. In contrast, labeling of benign eccrine tumors was more focal, tending to localize around ducts $(79 \%, \mathrm{n}=19)$. Microcystic adnexal carcinoma demonstrated focal staining of deeper ductal structures $(71 \%, n=7)$, whereas desmoplastic trichoepithelioma and basal cell carcinoma showed only rare positive cells. All cases of mammary $(n=7)$ and extramammary $(\mathrm{n}=8)$ Paget's disease labeled diffusely for CD5. Pagetoid Bowen's disease $(\mathrm{n}=6)$, intraepidermal sebaceous carcinoma $(\mathrm{n}=3)$, nor melanoma in situ $(\mathrm{n}=6)$ showed any CD5 staining.

Conclusions: Immunohistochemical staining for CD5 is extremely useful in the differential diagnosis of pagetoid epidermal lesions and will mark mammary and extramammary Paget's disease, but not pagetoid Bowen's disease, melanoma in situ, or sebaceous carcinoma.

Bogner PN, Su LD, Fullen DR. Cluster designation 5 staining of normal and non-lymphoid neoplastic skin.

J Cutan Pathol 2005; 32: 50-54. (C) Blackwell Munksgaard 2005.
Paul N. Bogner ${ }^{1}$, Lyndon D. Su ${ }^{1,2}$ and Douglas R. Fullen ${ }^{1,2}$

${ }^{1}$ Department of Pathology, and 2Department of Dermatology, University of Michigan Medical Center, Ann Arbor, MI, USA

Douglas R. Fullen, MD, Department of Pathology, Division of Dermatopathology, University of Michigan Medical Center, M5230, Medical Sciences I, 1301 Catherine, Ann Arbor, Ml 48109-0602, USA Tel: +17347644460

Fax: +17349362756

e-mail: dfullen@umich.edu

Accepted for publication May 6, 2004
Cluster designation 5 (CD5) is a transmembrane, signal-transducing glycoprotein originally identified on lymphocytes. ${ }^{1,2}$ More recently, immunohistochemical detection of GD5 has been reported in non-lymphoid tumors. Most of the initial non-lymphoid tumors showing CD5 staining were thymic in origin. ${ }^{3-7}$ Early work with non-thymic, non-lymphoid neoplasms showed no CD5 staining in any of the 61 tumors examined (using the CD5/54/B4 antibody clone). ${ }^{6}$ Subsequently, Kornstein and Rosai also studied non-thymic, nonlymphoid neoplasms and found that $4 \%$ of 386 tumors

* These findings were presented in abstract form at the 2003 Annual Meeting of the American Society of Dermatopathology (ASDP). stained for CD5 using a second CD5 monoclonal antibody clone (clone 4C7). Interestingly, none of this same group of tumors stained with the CD5/54/B4 clone. The tumors staining with CD5-4C7 included a diverse array of adenocarcinomas (gastric, endometrial, and salivary polymorphous low-grade), a small bowel carcinoid, two papillary thyroid carcinomas, and a uterine leiomyosarcoma. ${ }^{8}$ Other investigators have reported CD5 staining in normal and neoplastic breast tissue, primarily using CD5-4C7.,, 10

In using CD5 for the routine evaluation of cutaneous lymphoid lesions, ${ }^{11}$ we observed that eccrine glands stained strongly with the 4C7 clone utilized by University of Michigan, Immunohistochemistry 
CD5 staining of normal and non-lymphoid neoplastic skin

laboratory. It seemed promising therefore to evaluate a larger group of cutaneous neoplasms of different lineages. Our goal was to study in more detail the distribution of CD5 in normal skin and in a variety of cutaneous tumors. Although our primary focus was on ductal (apocrine and eccrine) tumors and pagetoid epidermal lesions, we also examined morpheaform basal cell carcinoma (BCG) and desmoplastic trichoepithelioma. These latter two entities were included because of their histologic resemblance to the infiltrative basaloid cells of microcystic adnexal carcinoma (MAC), especially on superficial biopsy.

\section{Methods}

The pathology database of the University of Michigan Medical Center was searched between 1995 and 2002 to identify multiple examples of cutaneous eccrine, apocrine, follicular, and epithelial tumors. Additionally, a variety of mammary and extramammary pagetoid intraepidermal lesions from this same period were identified.

In total, we examined 105 lesional biopsies for CD5 staining. Of these, 18 showed histologic evidence of apocrine differentiation (cuboidal to columnar cells with eosinophilic cytoplasm and decapitation secretion). Likewise, 34 cases showed standard eccrine histologic features. For the reasons outlined earlier, we also stained morpheaform (aggressive growth pattern) BCC and desmoplastic trichoepithelioma $(n=20$ and 11 , respectively). Finally, a comparison of pagetoid intraepidermal lesions included mammary Paget's disease $(n=7)$, extramammary Paget's disease $(n=7)$, pagetoid Bowen's disease $(n=6)$, pagetoid melanoma in situ $(\mathrm{n}=6)$, and sebaceous carcinoma with pagetoid spread $(\mathrm{n}=3)$. All of the lesions examined are listed in Table 1.

After a review of the original diagnosis and hematoxylin and eosin-stained slides, immunohistochemical staining for CD5 was performed on the archived paraffin tissue blocks. Five-micron sections were stained using an anti-human mouse monoclonal antibody (1:50 dilution, clone 4C7, Novocastra Labs, Newcastle upon Tyne, UK). Slides were pretreated with $0.25 \mathrm{~m}$ Tris $-0.1 \mathrm{~mm}$ ethylenediaminetetraacetic acid buffer ( $\mathrm{pH}$ 9.0) in a microwave pressure cooker for 15 min. Staining was performed on a Ventana ES system (Ventana Medical Systems, Tucson, AZ, USA) using the Ventana High Intensity DAB (3,3'diaminobenzidine tetrahydrochloride) kit.

Stained slides were then reviewed to assess staining pattern and intensity. The intensity of positive cytoplasmic staining was graded on a two-point scale $(1+$ weak staining, $2+$ strong staining). Additionally, the percentage of positive lesional cells was placed in one of four categories: $>75 \%, 25-75 \%, 1-25 \%$, and $<1 \%$. For each slide, a positive internal control was identified, usually CD5-positive dermal lymphocytes.

This retrospective study was reviewed and approved by the University of Michigan Institutional Review Board for Human Subject Research.

\section{Results}

We examined normal cutaneous structures for CD5 staining. In addition to occasional CD5-positive lymphoid cells, we found consistent and strong staining of the eccrine and apocrine secretory units (Fig. 1).

Table 1. Cluster designation 5 (CD5) staining of cases classified by diagnosis

\begin{tabular}{|c|c|c|c|c|c|c|c|c|c|}
\hline \multirow[b]{2}{*}{ Origin } & \multirow[b]{2}{*}{ Tumor } & \multirow[b]{2}{*}{$\mathrm{n}$} & \multicolumn{5}{|c|}{ Percentage of cells positive for CD5 } & \multicolumn{2}{|c|}{ Intensity of positive staining } \\
\hline & & & $>75$ & $25-75$ & $1-25$ & $<1$ & Negative & $2+$ & $1+$ \\
\hline \multirow[t]{6}{*}{ Apocrine/eccrine } & $\begin{array}{l}\text { Apocrine hidradenoma } \\
\text { Hidradenoma papilliferum } \\
\text { Syringocystadenoma papilliferum }\end{array}$ & $\begin{array}{l}3 \\
5 \\
2\end{array}$ & $\begin{array}{l}0 \\
5 \\
1\end{array}$ & $\begin{array}{l}3 \\
0 \\
0\end{array}$ & $\begin{array}{l}0 \\
0 \\
1\end{array}$ & $\begin{array}{l}0 \\
0 \\
0\end{array}$ & $\begin{array}{l}0 \\
0 \\
0\end{array}$ & $\begin{array}{l}3 \\
5 \\
2\end{array}$ & $\begin{array}{l}0 \\
0 \\
0\end{array}$ \\
\hline & Hidradenocarcinoma & 1 & 1 & 0 & 0 & 0 & 0 & 1 & 0 \\
\hline & $\begin{array}{l}\text { Cylindroma/spiradenoma } \\
\text { Syringoma } \\
\text { Microcystic adenexal carcinoma }\end{array}$ & $\begin{array}{l}5 \\
4 \\
7\end{array}$ & $\begin{array}{l}0 \\
0 \\
0\end{array}$ & $\begin{array}{l}1 \\
0 \\
2\end{array}$ & $\begin{array}{l}4 \\
1 \\
2\end{array}$ & $\begin{array}{l}0 \\
0 \\
1\end{array}$ & $\begin{array}{l}0 \\
3 \\
2\end{array}$ & $\begin{array}{l}5 \\
0 \\
4\end{array}$ & $\begin{array}{l}0 \\
1 \\
1\end{array}$ \\
\hline & $\begin{array}{l}\text { Eccrine hidradenoma } \\
\text { Poroma }\end{array}$ & $\begin{array}{l}5 \\
5\end{array}$ & $\begin{array}{l}0 \\
0\end{array}$ & $\begin{array}{l}0 \\
0\end{array}$ & $\begin{array}{l}2 \\
4\end{array}$ & $\begin{array}{l}2 \\
1\end{array}$ & $\begin{array}{l}1 \\
0\end{array}$ & $\begin{array}{l}3 \\
5\end{array}$ & $\begin{array}{l}1 \\
0\end{array}$ \\
\hline & $\begin{array}{l}\text { Atypical eccrine tumor } \\
\text { Eccrine carcinoma } \\
\text { Aggressive digital papillary adenocarcinoma } \\
\text { Mucinous carcinoma }\end{array}$ & $\begin{array}{l}2 \\
1 \\
2 \\
3\end{array}$ & $\begin{array}{l}0 \\
0 \\
1 \\
1\end{array}$ & $\begin{array}{l}0 \\
0 \\
0 \\
2\end{array}$ & $\begin{array}{l}2 \\
0 \\
0 \\
0\end{array}$ & $\begin{array}{l}0 \\
0 \\
0 \\
0\end{array}$ & $\begin{array}{l}0 \\
1 \\
1 \\
0\end{array}$ & $\begin{array}{l}2 \\
0 \\
1 \\
3\end{array}$ & $\begin{array}{l}0 \\
0 \\
0 \\
0\end{array}$ \\
\hline & Total & 45 & 9 & 8 & 16 & 4 & 8 & 34 & 3 \\
\hline Epithelial & Basal cell carcinoma & 20 & 0 & 0 & 1 & 2 & 17 & 2 & 1 \\
\hline Follicular & Desmoplastic trichoepithelioma & 11 & 0 & 0 & 1 & 3 & 7 & 1 & 3 \\
\hline Pagetoid & $\begin{array}{l}\text { Mammary Paget's disease } \\
\text { Extramammary Paget's disease } \\
\text { Pagetoid Bowen's disease } \\
\text { Melanoma in situ } \\
\text { Sebaceous carcinoma with pagetoid spread }\end{array}$ & $\begin{array}{l}7 \\
7 \\
6 \\
6 \\
3\end{array}$ & $\begin{array}{l}6 \\
7 \\
0 \\
0 \\
0\end{array}$ & $\begin{array}{l}1 \\
0 \\
0 \\
0 \\
0\end{array}$ & $\begin{array}{l}0 \\
0 \\
0 \\
0 \\
0\end{array}$ & $\begin{array}{l}0 \\
0 \\
0 \\
0 \\
0\end{array}$ & $\begin{array}{l}0 \\
0 \\
6 \\
6 \\
3\end{array}$ & $\begin{array}{l}5 \\
6 \\
0 \\
0 \\
0\end{array}$ & $\begin{array}{l}2 \\
1 \\
0 \\
0 \\
0\end{array}$ \\
\hline
\end{tabular}


Bogner et al.

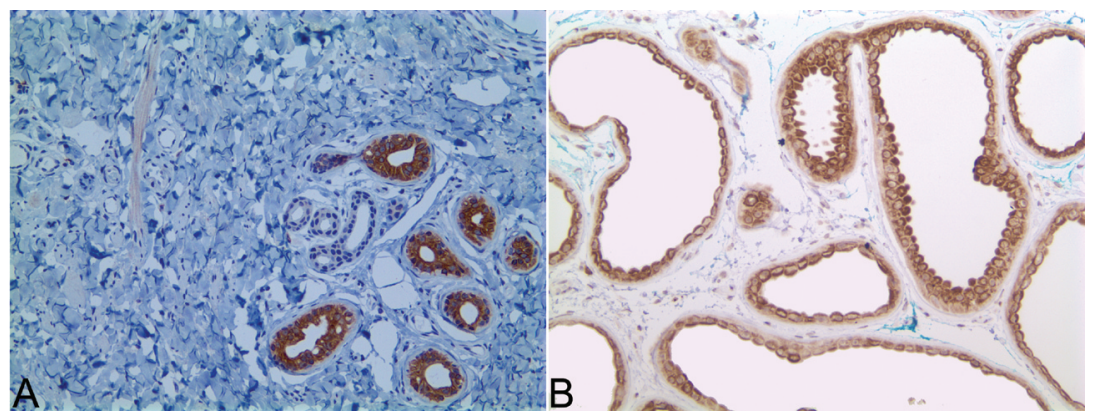

Fig. 1. A) The eccrine secretory unit stains strongly for cluster designation 5 (CD5), while adjacent eccrine duct is negative $(\times 200)$. B) Normal apocrine glands show strong CD5 staining $(\times 200)$.

Interestingly, the eccrine duct and acrosyringium were CD5 negative. Follicular epithelium and the sebaceous units were also negative, as was the epidermis. The only other cutaneous structure that stained, albeit weakly, was pilar smooth muscle. Stromal cells in the dermis were uniformly negative for CD5.

Tumors with apocrine differentiation showed generally diffuse $(>75 \%$ of lesional cells) and strong $(2+)$
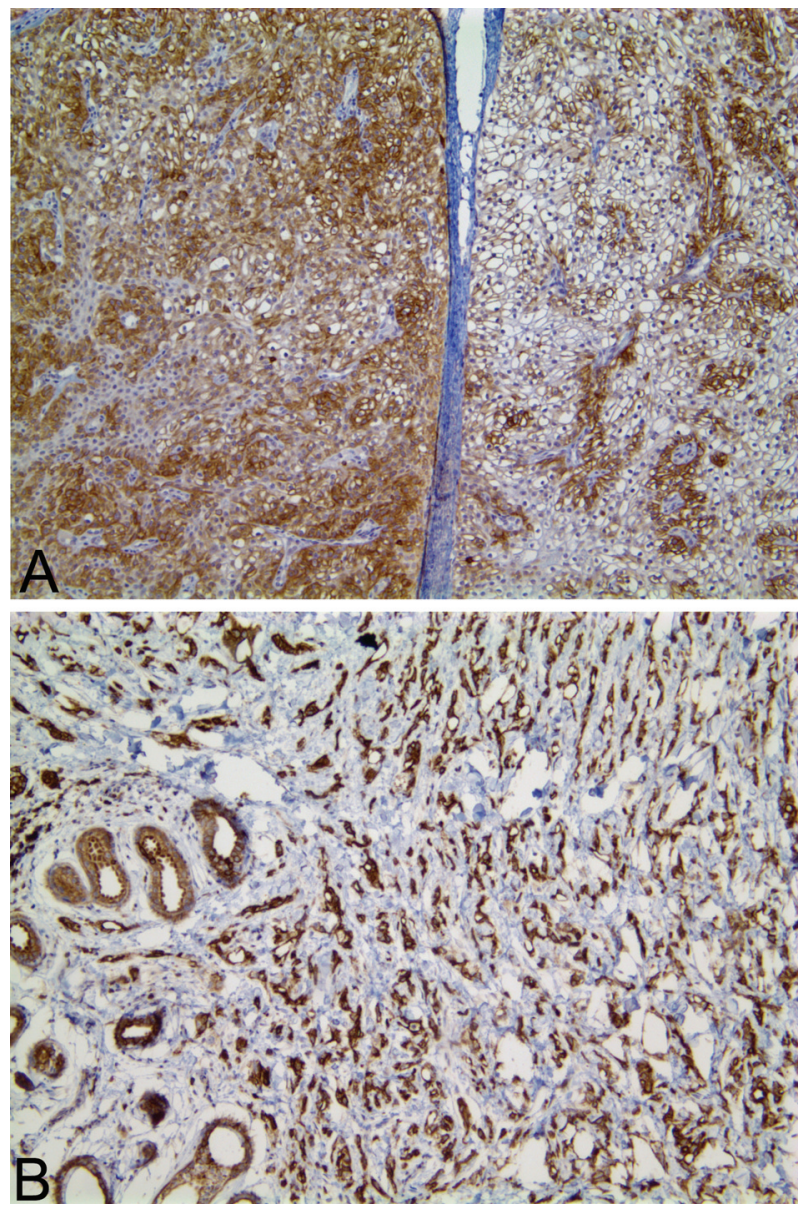

Fig. 2. A) Hidradenoma with apocrine differentiation showing strong $(2+)$, diffuse staining for cluster designation $5(\times 100)$. B) Adenocarcinoma with apocrine differentiation also shows strong, diffuse staining $(\times 100)$. cytoplasmic staining (Fig. 2). The three examples of hidradenoma with apocrine differentiation showed the least staining, with $25-75 \%$ of the lesional cells marking for CD5. One case of syringocystadenoma papilliferum also had a low percentage $(1-25 \%)$ of lesional cells labeling with CD5.

Tumors with eccrine morphology showed less consistent staining. Most of these tumors (27/34) showed focal $(<25 \%$ of lesional cells) or no staining. Despite the patchy staining, individual cells marked just as strongly $(2+$ in $23 / 26$ tumors with positive cells) as those in apocrine-appearing tumors. The CD5positive cells tended to localize around ductal- or glandular-type structures (Fig. 3).

The majority of the examples of MAC stained focally $(<75 \%$ in $5 / 7$ cases), but strongly $(2+$ in $4 / 5$ positive cases). CD5 staining in MACs was most apparent in the deeper portions of the lesion. Only three of the 20 BCGs showed any CD5-positive cells, and these were very rare. Similarly, a minority of desmoplastic trichoepitheliomas (4/11) showed rare CD5-positive cells. Careful inspection confirmed

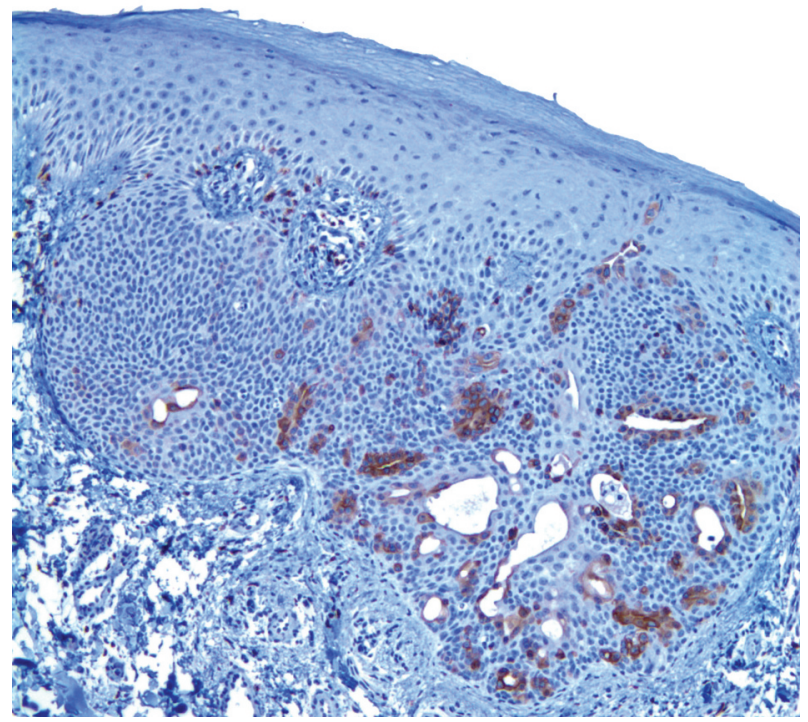

Fig. 3. Poroma shows strong (2+), focal staining around ductal structures $(\times 100)$. 


\section{CD5 staining of normal and non-lymphoid neoplastic skin}

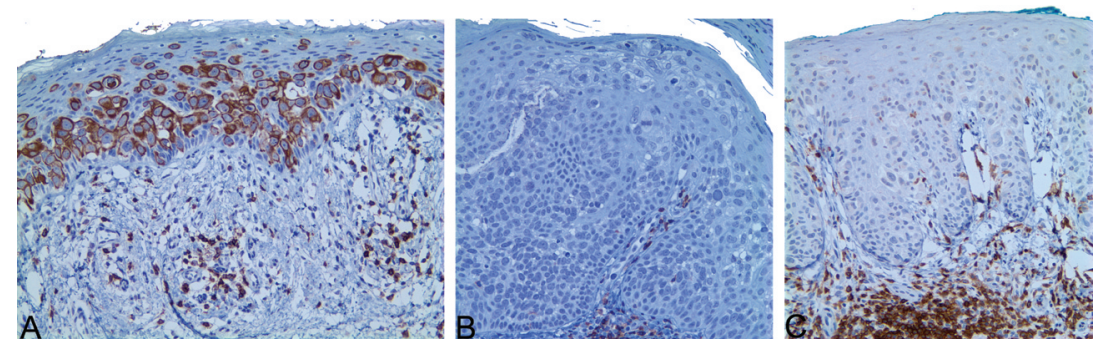

Fig. 4. A) The neoplastic cells of mammary Paget's disease stain strongly (2+) for cluster designation 5 (CD5) (×200). B) There is no CD5 staining of the dysplastic squamous epithelium of pagetoid Bowen's disease ( $\times 200)$. C) Pagetoid melanoma in situ shows no CD5 staining of the neoplastic melanocytes $(\times 200)$. CD5-positive dermal lymphocytes are present in all three cases.

staining of tumor cells and not tumor-infiltrating lymphocytes.

CD5 stained the neoplastic cells of both mammary and extramammary Paget's disease diffusely $(>75 \%$ in $6 / 7$ and $7 / 7$, respectively) and strongly $(2+$ in $5 / 7$ and $6 / 7$, respectively). In stark contrast, none of the other pagetoid lesions showed any staining (Fig. 4). All the data are summarized in Table 1.

\section{Discussion}

Our study appears to be the first examination of CD5 staining within normal and non-lymphoid neoplastic skin. To some extent, our findings correlate with those of previous studies, in that CD5 stains certain types of glandular but not squamous epithelium. ${ }^{8}$ When present, diffuse CD5 staining appears to be useful in discriminating eccrine, apocrine, and other glandular lesions from histologically similar epidermal and follicular tumors.

Despite the more diffuse staining of tumors with apocrine differentiation, this on its own is probably not reliable enough a phenomenon to specifically categorize a given lesion as apocrine instead of eccrine. This is not surprising, because normal apocrine and eccrine secretory glands both stain for CD5. CD5 staining therefore does not appear to contribute significantly to the broader problems of adnexal tumor classification.

We were also interested in evaluating the utility of CD5 staining in differentiating MAC from desmoplastic trichoepithelioma and morpheaform BCC (aggressive growth pattern). Although the majority of the MACs we examined did stain with CD5, some of the trichoepitheliomas and BCGs also showed rareto-focal staining of tumor cells. As staining of MAC was somewhat variable (and occasionally negative), scattered CD5 staining does not significantly narrow the differential diagnosis. Furthermore, CD5 labeling of MAC tended to localize to the deeper portions of tumor that may be absent in a superficial biopsy. Despite these limitations, strong staining with CD5 appears to favor MAC in the differential diagnosis of these infiltrative dermal tumors.
Finally, CD5 staining appears most useful in the differential diagnosis of pagetoid epithelial lesions. The staining of mammary and extramammary Paget's disease was generally strong and diffuse, as would be expected in neoplastic proliferations of purported apocrine origin. Pagetoid spread of superficial spreading melanoma, pagetoid Bowen's disease, and intraepidermal sebaceous carcinoma, in contrast, were universally negative for CD5 staining. Admittedly, we did not compare the overall sensitivity and specificity of CD5 with those of other antibodies used for mammary and extramammary Paget's disease (polyclonal carcinoembryonic antigen, cytokeratin 7, and others). Nonetheless, CD5 may represent a useful addition to an antibody panel for differentiating mammary and extramammary Paget's disease from histologically similar pagetoid epidermal lesions.

\section{References}

1. Itakura K, Hutton JJ, Boyse EA, Old LJ. Linkage groups of the theta and Ly-A loci. Nat New Biol 1971; 230: 126.

2. Morse HC. Genetic nomenclature for loci controlling surface antigens of mouse hemopoietic cells. J Immunol 1992; 149: 3129.

3. Hishima T, Fukayama M, Fujisawa M, et al. CD5 expression in thymic carcinoma. Am J Pathol 1994; 145: 268.

4. Berezowski K, Grimes MM, Gal A, et al. CD5 immunoreactivity of epithelial cells in thymic carcinoma and CASTLE using paraffin-embedded tissue. Am J Clin Pathol 1996; 106: 483.

5. Kuo TT, Chan JK. Thymic carcinoma arising in thymomas is associated with alterations in immunohistochemical profile. Am J Surg Pathol 1998; 22: 1474.

6. Dorfman DM, Shahsafaei A, Chan JK. Thymic carcinomas, but not thymomas and carcinomas of other sites, show CD5 immunoreactivity. Am J Surg Pathol 1997; 21: 936.

7. Tateyama H, Eimoto T, Tada T, et al. Immunoreactivity of a new CD5 antibody with normal epithelium and malignant tumors including thymic carcinoma. Am J Clin Pathol 1999; 111: 235.

8. Kornstein MJ, RosaiJ. CD5 labeling of thymic carcinomas and other nonlymphoid neoplasms. Am J Clin Pathol 1998; 109: 722.

9. Shousha S, Costello C, Luqmani YA, et al. CD5 positive breast carcinoma in a patient with untreated chronic lymphocytic leukaemia: molecular studies of chromosome 13q.J Clin Pathol 1998; 51: 862. 


\section{Bogner et al.}

10. Walsh R, Peston D, Shousha S. Comparison of immunoperoxidase staining of 3 different types of CD5 antibodies in a spectrum of breast lesions. Arch Pathol Lab Med 2001; 125: 781.

11. Fung MA, Murphy MJ, Hoss DM, et al. Practical evaluation and management of cutaneous lymphoma. J Am Acad Dermatol 2002; 46: 325. 